\title{
Transitioning from Data Storage to Data Curation: The Challenges Facing an Archaeological Institution
}

\author{
Maria Sagrario R. Simbulan \\ University of the Philippines, Diliman, Quezon City, Philippines
}

msrsimbulan@up.edu.ph

\begin{abstract}
Each archaeological project generates substantial amounts of data from season to season, all of which need to be collected, analyzed, organized, and stored. After an archaeological project or season ends and all the accessioning-related and analytical activities are completed, all those artifacts are stored away in shelves, boxes and crates, and the associated archaeological data will be stored as digital files and in file folders. There are two critical questions in a time of downsized organizations and shrinking budgets: How can the archaeological data and related scientific information pertaining to each of these archaeological projects be preserved and made available to other researchers? How do we make sure that future generations are able to access these information resources?

I ask these questions as a relative newcomer to archaeology. This paper is a quest to understand how archaeological institutions can transition from an individually curated, per project/per season information gathering and data storage approach to a centralized information resource management approach known as archaeological data curation. Specifically, this paper will look at the challenges that an archaeological institution would face as it attempts to shift from narrowlyfocused, project-related data storage to a broader and long-term focus on the management of the archaeological information resources of the entire institution.
\end{abstract}

Keywords: data curation, data repositories, archaeological data curation, digital curation

\section{Introduction}

Archaeological activities, whether in the field or in the laboratory, generate significant amounts of data. To cope with the ever-expanding amounts of data, archaeological institutions need to carefully manage their information resources for historical (and bureaucratic) purposes as well as to organize data for easy retrieval, allowing data to be shared with colleagues and the interested public, and to be used for research and publication.

This makes it imperative for any institution engaged in archaeological investigations to carefully manage its information resources. An equally important responsibility is to ensure that data col-

Material published as part of this publication, either on-line or in print, is copyrighted by the Informing Science Institute. Permission to make digital or paper copy of part or all of these works for personal or classroom use is granted without fee provided that the copies are not made or distributed for profit or commercial advantage AND that copies 1) bear this notice in full and 2) give the full citation on the first page. It is permissible to abstract these works so long as credit is given. To copy in all other cases or to republish or to post on a server or to redistribute to lists requires specific permission and payment of a fee. Contact Publisher@InformingScience.org to request redistribution permission. lected during any of the institution's projects remain live for extended periods of time or be archived in a manner that ensures quick access should there be any need for the archived data (Greene, 1995; Lock, 2003; Ryan, n.d.).

Written from the perspective of an IT professional with over twenty-five years of experience in programming and in systems analysis and design who is cur- 
rently training to become a professional archaeologist, this paper explores what a fifteen year old archaeological institution with rather fragmented information resources (in that project-related information are personally curated by individual archaeologists) needs to do to transition to a more centrally organized, institutionally curated approach to manage its information resources.

Beyond its expected academic and research functions, part of this institution's mandate is to be the leading archaeological research institution in the country. Given the current budgetary and manpower constraints that affect practically all academic and research organizations around the world, finding ways to effectively manage its information resources and still deliver on its mandate is a top priority of this institution's administrators.

This paper is not about the whole process of scientific archaeological inquiry but is only concerned with what happens to the primary data gathered in the field during digs as well as to the data generated as a result of analytical techniques and procedures employed in archaeological laboratories post-dig. After an archaeological project or season ends and all the accessioningrelated and analytical activities are completed, all those artifacts are stored away in shelves, boxes and crates, and the associated archaeological data will be stored as digital files and in file folders. Beyond reports and inventories submitted to the National Museum and funding institutions, the public gets to learn about these discoveries and research results through published reports, news features, or through museum exhibits. There are two critical questions: In a time of downsized organizations and shrinking budgets, how can the archaeological data and related scientific information pertaining to each of these archaeological projects be preserved and made available to other researchers? How do we make sure that future generations are able to access these information resources?

I ask these questions as a relative newcomer to archaeology. This paper is a quest to understand how archaeological institutions can transition from an individually curated, per project/per season information gathering and data storage approach to a centralized information resource management approach known as institutional data curation. Specifically, this paper will look at the challenges that archaeological institutions face as they attempt to shift from narrowly-focused projectrelated data storage concerns to a broader and long-term focus on the management of the archaeological information resources of the entire institution.

\section{Discussion}

\section{The Nature of Archaeological Data}

Archaeological data consists of observations about artifacts and their contexts. Archaeological sites, especially those which present clear evidence of past human activity and occupation, are investigated over many years. Each archaeological project, led by a professional archaeologist as project director, generates substantial amounts of archaeological data from season to season, all of which need to be collected, analyzed, organized, and stored. Each stage in an archaeological investigation - from planning, excavation, to post-excavation analysis - generates data, lots of it.

During the actual excavation, material remains can be recovered which might allow archaeologists to reconstruct aspects of past cultures and ways of life. Material remains include three types of data - artifacts, features, and ecofacts. An artifact is a portable, material thing made or modified by human action. It includes objects, such as tools, weapons and ornaments. Features are non-portable artifacts that cannot be moved about but that were constructed or modified by the people who occupied the archaeological site. Typical examples of archaeological features include pits, ditches, middens (trash heaps), buildings, graves, house foundations, fortifications, hearths, postholes, and field boundaries. Ecofacts are non-artifactual organic and environmental remains that provide information on environments and the ways they were used by early peoples. Com- 
mon types of ecofacts include faunal remains, seeds and other plant remains, and plant pollen. (Richards \& Ryan, 1985:13; Crankshaft Publishing, n.d.).

In addition to data on the material remains recovered during a dig, measurements relating to the site, context, stratigraphy, and geographical location need to be meticulously recorded. A site is defined as any concentration of artifacts, ecofacts, or features that marks a location of past human activity. The context of an artifact consists of its matrix (the material, such as particular layer of soil, surrounding it), its provenience (horizontal and vertical position within the matrix), and its association with other artifacts found nearby. Archaeological stratigraphy is refers to a series of layers and cuts within trenches that form a ranked sequence of 'containers', each bearing its own artifact assemblage (Renfrew \& Bahn, 2008).

After excavation, a range of analytical techniques that vary depending on the type of artifact, material, or sample being studied are used to discover as much archaeological data as possible about the site, the finds, and the context in which these artifacts and archaeological evidence are found. Environmental samples and ecofacts, once removed from soil, are identified by species and then analyzed in similar ways, using microscopes for plant and invertebrate remains. Once identified and categorized material is quantified and recorded through drawing or photography. A descriptive report is then produced by the specialist undertaking the work (Grant et al, 2008: 64-65). Beyond maintaining artifact-related information in spreadsheets or databases, archaeologists and staff associated with a project need to collect and organize artifact photos, field photos, paper forms, sketches, maps, stratigraphic information, and geophysical data, among others (Anderson, Miller \& Yerka, 2011).

All of the archaeological data and information generated during a field season must be recorded, stored and organized, with every season's data distinct from the other seasons' data. Since it is usual for archaeological sites to be excavated over several seasons in the very least, with some especially rich sites exceeding a hundred seasons, the ability to ensure the long term accessibility and preservation of archaeological data is an important responsibility of organizations engaged in archaeology (Niven \& Thompson, 2011). This is an extremely important responsibility given that the very same fieldwork that is the source of the artifacts and associated data also destroys the archaeological site and with it all traces of human activity and settlement. Simply put, you cannot dig a site twice.

Since the archaeological record is probably our only way to access most of human history and prehistory, it is imperative that archaeological research materials - the artifacts, environmental and dating samples, field documentation, records, notes, catalogs, laboratory documentation, photographic records, drawings, related historical documents, and reports - be stored appropriately and remain accessible to researchers and to future generations. It is this ethical obligation to preserve the artifacts and data collected during archaeological projects that drives the need to effectively manage archaeological information resources.

\section{Managing Archaeological Information Resources}

The need to manage an information resource or a body of data has been around for a very long time in all types of organizations - ever since people realized there needed to be a way to help them organize information that was important to their lives and their livelihood. The initial efforts were informal and often did not involve any methodology and only minimal technology. Each researcher or data user was responsible for his/her own data collection and storage, devising their own methods and procedures to cope with ever-increasing amounts of data. Over the years, many terms have been used to describe the various efforts to collect, organize, and store data and information: data storage, data management, information management, and information resource management. 
Information is the life-blood of any organization. So if organizations are to fully utilize and manage their information and information systems there needs to be a focus placed on what is information, what does it mean to an organization, and how do the people in an organization make use of it (Knox, 2007). Horton (1981) described information resources as encompassing all of the specialists, facilities, supplies, hardware, and software which an organization employs to collect, handle, store, disseminate, and use its data and information. Goldfine (1982) defined information resource management as whatever policy, action, or procedure concerning information (both automated and non-automated) which management establishes to serve the overall current and future needs of the organization. According to Beachboard \& Ayres (2011), the first principle of IRM was that information management needed to better balance the concerns of introducing new technologies and media with the treatment of information as a key resource and the second principle of IRM required managers to deal with information not just as a set of objects or artifacts such as data or files, but also as a process that extended from information's identification (sensing), collection, and organization through its processing, use and maintenance.

The modern concept of information resource management (IRM) as a tool arose from a U.S. government initiative to reduce paperwork (Horton, 1981; Miller, 1981; Guimaraes, 1985). It was in the mid-1970s that information began to be recognized as an entity independent of the technology used to gather and manipulate it. People realized that information was a significant organizational resource and sought to find ways to manage it and maximize the value they could derive from it (Marchand, 1978; Trauth, 1988). With the help of increasingly efficient computing and communications technologies, IRM efforts worked well; that is, until organizations began to drown in oceans of data and information.

Academic and research institutions called the overwhelming amounts of data and information generated by scientific research projects an 'embarrassment of riches'. They focused on simple data storage solutions to deal with the problem. Aside from physical storage facilities (in the case of archaeological institutions, these were storage racks stacked with boxes and boxes of artifacts and related paperwork), computer-based magnetic and optical storage technologies like magnetic tapes, hard disks, and compact disks (CDs) were used to reduce the physical space occupied by paper-based research materials. Various computer hardware and software applications were later introduced and actively used over many years to store research data - but it was this variety of computer hardware, software, and file formats that would become a major headache for these institutions in the future since proprietary file formats could not be migrated to more current ones supported by newer hardware and software.

It is important to highlight the fact that their concept of data storage was simply about keeping data in existence in the short term and ensuring that it can be accessed when needed. Without a long term plan to curate the data at the institutional level, each research project or unit ended up having its own data storage procedures and facilities. This resulted in islands of research data and information within the institutions that could only be accessed and used by the primary research project team members but not by other researchers. The lack of a clear concept of institutional data curation and the absence of data access policies governing data and information generated from institutionally funded research created situations supporting the practice of personal curation of these information resources by individual researchers.

Today, the problem facing researchers and administrators of research collections (including academic and industrial research) isn't just about data acquisition, data storage and basic information management - the research data needs to be accessible, quickly and easily usable by researchers, and securely stored for future cultural, educational, and scientific purposes (Hemsoth, 2012a). This is essentially what data curation is all about. 
According to the University of Illinois' Graduate School of Library and Information Science (GSLIS), data curation is the active and ongoing management of data through its lifecycle of interest and usefulness to scholarship, science, and education. Data curation enables data discovery and retrieval, maintains data quality, adds value, and provides for re-use over time through activities including authentication, archiving, management, preservation, and representation (GSLIS, n.d.; Hemsoth, 2012b).

Given the amount of effort and expense associated with data curation, why curate research data? Day (2010) and Boock \& Chadwell (2010) offered several reasons:

- Data curation fits into and is part of the normal research process, specifically the need for others to validate and replicate research. The authors point out that the principles of sharing and openness are firmly embedded in some disciplines.

- Data curation protects the extrinsic and intrinsic value of research data. The high level of investments that academic and scientific organizations put into research projects means that data can be very expensive to capture and analyze. Data curation helps protect this investment by ensuring that the data is safe yet accessible to all who need to use it. Data curation recognizes that data, especially observational data, is impossible to recreate once lost.

- Data curation helps researchers take advantage of the potential for creating 'new' knowledge from existing data. Some of the methods of new knowledge creation involve data re-use, data re-analysis, data mining, and combining datasets in innovative ways with research results obtained using new analytical tools and technologies. Prime examples in the archaeological discipline is the application of GIS, Remote sensing, and 3D laser technologies to obtain new insights into human history and prehistory using data gathered many years, sometimes decades, ago.

- Data curation is increasingly a requirement of research funding bodies. Some of these organizations have mature data retention policies. There is an increasing expectation of open access to data from publicly-funded research.

- Data curation is central to institutional asset management. Universities and other research organizations invest very large sums of money into research activities Research data is a key output of this activity. It is, therefore, an institutional asset that needs stewardship.

- Data curation plays a role in promoting the institution, the research group or the individual researcher. Re-use of research data helps promote visibility and 'impact'. Institutions that curate data and make these available for re-analysis and reuse can become acknowledged 'centers of competence'.

Archaeologists have an ethical obligation to preserve the data they collect during archaeological projects for future generations, according to The Society for Historical Archaeology's Standards and Guidelines for the Curation of Archaeological Collections (1993). According to the Society, data curation should be an integral element of the archaeological process and should include the long-term management and preservation of archaeological materials as well as their associated data and documentation.

Carole Palmer (2010) highlighted the fact that presently there's a lot of recognition of the value of research data as assets to research institutions and to the scientific enterprise. Storing only the publications that report the results of research simply isn't enough anymore. Researchers also need access to data that can be integrated and re-used in new ways. This is especially important in data-intensive sciences, where the power of discovery lies in applying computational approaches to large, aggregated data sets. According to Palmer, researchers need to start thinking about data 
management requirements from the very beginning of their projects, and to think in terms of a data set's lifecycle. Data curation emphasizes the lifecycle - managing and preserving data for the long term, and that process begins long before data are generated. Palmer suggested that data curation needs to be introduced at the research proposal stage to make sure a viable data management plan is in place at the outset of a project.

Systematic data curation includes documenting the context in which data were generated or derived, including the instruments involved, the protocols and such. It also requires caring for the data and making them available to other scientists. While expensive and labor intensive, a good reason in favor of collecting and curating data is the issue of replication and validation of a research project's conclusions. The data curation process ensures the science is reproducible, but it's also about finding ways to bring data together from different sources and using them in new ways (Waraksa, 2011). To replicate a study or re-use data you have to know where a data set came from and how it's been processed. Tracking all the context and data transformations is part of the data curation process.

While many institutions choose to curate their data resources in-house (using institutional libraries as the lead unit), other organizations engaged in archaeology elect to use external data repositories to house their data sets and all important documentation pertaining to archaeological projects. The Archaeology Data Service (ADS) in the UK and The Digital Archaeological Record (tDAR) in the USA are two examples. These repositories that operate on a global scale house incredibly large collections of critical archaeological data such as 3D scans of artifacts to more traditional archaeological research materials, including digitized books and scholarly papers (Hemsoth, 2012b). There may be fees, though, that need to be paid on a regular basis, as well as data quality standards to be met before an institution's data is accepted for curation and preservation in such repositories.

While researchers and academic institutions have highly developed mechanisms for transferring knowledge among themselves, there seems to be a considerable lag in facilitating the distribution of research results beyond research communities. The World Wide Web provides a potential solution to this problem, as it provides a global information infrastructure for connecting those who produce knowledge - scientists and researchers - and those who need to apply this knowledge users, the general public, and practitioners (Moody, 2003). Increasingly, concern for the provision of permanent universal access to research data has many scientists and researchers supporting initiatives provide open access to research data via the Internet and the World-Wide Web (WWW). These research data, housed in digital repositories or digital archives, may include digitized analogue and digital field data, data generated through laboratory analysis, GIS data, as well as multimedia and photographs (digitized as well as born-digital images). Open data and content can be freely used, reused and redistributed by anyone - subject only, at most, to the requirement to attribute and share-alike (opendefinition.org, n.d.).

Organizations such as the DataBib.org and re3data re3data.org are global registries of research data repositories. While not actual data repositories, these registries provide organized and searchable listings of research data repositories from different academic disciplines. Databib is a web-based tool for helping people identify and locate online repositories of research data. In Databib, users and bibliographers create and curate records that describe the data repositories (currently numbering 519) that users can search (Databib.org, n.d.). re3data.org (Registry of Research Data Repositories) lists repositories for the permanent storage and access of data sets to researchers, funding bodies, publishers and scholarly institutions. re3data.org aims to promote a culture of sharing, increased access and better visibility of research data (re3data.org, n.d.).

As tools to promote data curation, online digital repositories as well as the online tools to help interested parties locate research data and content deposited within such repositories offer signifi- 
cant benefits such as enabling easy, simultaneous and remote access to research data deposits, allowing institutions to efficiently retain and manage their own intellectual assets, facilitating reuse of deposited materials for new research, education, and learning, minimizing physical storage requirements, and enabling external validation of research results (Semple, 2006).

It is important to point out that data curation entails a serious institutional commitment of funds and manpower. It requires that an institutional data policy is in place and that management is committed to and supportive of the whole data curation process (Bustard, 2000; Palmer, 2010; Sullivan \& Childs, 2003).

\section{Archaeological Data Curation: The Challenges}

Based on the foregoing discussion, what can a fifteen year old archaeological institution do to transition from personally curated project-related information to a more centrally organized, institutionally curated approach to manage its information resources? The following are some of the challenges that this archaeological institution needs to overcome:

\section{Developing and implementing a data policy}

The first step in the transition to institutional data curation is developing a data policy suited to the institution's culture, work practices and organizational structure. According to the Data Curation Centre's (DCC) Sarah Jones (2009), the people crafting the policy should consider the policy's purpose and scope, the roles and responsibilities, implementation concerns like additional infrastructure and support service requirements, and institutionalizing a periodic review process to ensure that the data curation efforts still meet the needs and goals of the organization. Some of the following data policy creation guidelines are excerpts from the DCC's Curation Policy Report:

- To help ensure researcher and staff buy-in, the purpose or rationale of a data policy must reflect the institution's mission statement. The scope should be clearly defined as to the type of research outputs covered by the policy, the curation activities being addressed, and the context in which the policy is to be applied i.e. across an entire institution or just a single department or research project. Enforcing minimum standards of data quality will be crucial for cost-effectiveness.

- A data policy should define who will undertake the work and assign responsibility. By connecting policies with current activities, proposed tasks can be aligned with existing work practices, data flows, and staff skills. When assigning new responsibilities, changes should be thought through to ensure they are practical and implementable. Defining roles will also be important for accountability.

- Policies need to be accompanied by the appropriate services, skills and infrastructure if the data policy implementation is to be feasible. The wider context should also be considered: how does this policy fit in with and complement existing policies? An institutionwide activity to identify needs for the policy would raise awareness of the proposed policy and the work-related changes it would introduce. Implementing the data policy in phases could help test the appropriateness of the policy to the institution's work practices and culture. Phased implementation would allow policy adjustments and refinements to be made over time.

- Lastly, periodic reviews of the data policy will encourage researchers and staff to contribute their ideas and share experiences with an eye towards improving the data policy. Their involvement in this implementation and review process exerts a subtle push towards acceptance and willingness to work within the bounds of the policy. 
This archaeological institution does not need to create a data policy from scratch. Many sample policies, guides, and best practice exemplars are freely available from the websites of organizations like the Data Curation Centre (http://dcc.ac.uk), the Joint Information Systems Committee (http://jisc.ac.uk), the Association of Research Libraries (http://arl.org), the Australia National Data Services (http://ands.org.au), the Data Conservancy (http://dataconservancy.org), the Archaeology Data Service (http://archaeologydataservice.ac.uk), and the UK Data Archive (http://data-archive.ac.uk), among others. Many of the world's leading universities also host webpages with downloadable resources focusing on research data management and curation.

\section{Getting researcher and staff buy-in}

Initial reactions to the implementation of an institutional data curation policy will likely be either of two extremes: "But it's my data!" or "Where do I start? I have so much data!" According to the Stellagroup (2012), getting buy-in from researchers who often jealously guard their datasets fearing others will free ride on their data-collecting efforts and beat them to the publishing finishline is a challenge. They proposed some possible ways to meet this challenge such as:

- The creation of systems for reserving submitters' rights to first publication on datasets deposited in a repository

- Dataset publication/dataset depositing/dataset disclosure should be considered a contribution to be weighed in connection with tenure and promotion decisions

- Using the preceding suggestion as a carrot for data openness

Another possible way to tackle this challenge is to require new research proposals to include research data management plans. This way, at the outset of the project, the researcher agrees to work within the data management framework laid out in the institution's data policy.

\section{Obtaining funds to support the data curation effort}

Performing a cost benefit analysis (CBA) is a logical move for an institution transitioning to data curation. Involving researchers and staff in the process will enhance their appreciation of data curation, greatly increasing the chances of acceptance of the changes that data curation is sure to impose on the traditional work practices and data flows of the institution. The CBA will help estimate the level of funding that will need to be available to support the archaeological data curation implementation effort.

According to Mayernik (2012), the three main costs of running a data curation solution are hardware, staffing, and administrative costs. Hardware costs include the costs of purchasing and running servers, storage media, and the maintenance and servicing costs that accumulate over time. Hardware costs might also include additional costs/equipment necessary to create off-site back-up copies of data collections. Providing professional development opportunities for staff can be very beneficial to the individual staff members, and can help to improve and extend the services that an institution can provide, but must be accounted for in cost models. Administrative and operational costs also need to be taken into consideration. These costs include computer equipment, furniture, supplies, phones, and physical space charges.

It is important to ensure a long-term, sustainable commitment to the data curation project through all its phases. Data curation efforts will require access to computing facilities. Having adequate and long-term funding support means that resources and the equipment required to support the data curation implementation effort can be purchased and allocated in a timely fashion. In-house data curation eliminates the expense of external repository fees that eat up a large chunk of data curation-related budgets. With adequate funds, the staffing complement needed to support the data curation effort can be recruited, trained and deployed. User seminars will also be needed to 
get everyone comfortable with the new procedures that result from the implementation of the data policy.

Being part of a state-supported university, this institution can request for funding on an annual basis, equipment, and staff from the university. Given the current budgetary constraints, however, the financial support and access to equipment and human resources will likely be minimal. A second option is to apply for grants from foreign and domestic funding institutions. While there is a good likelihood of obtaining these grants given the excellent track record of this archaeological institution, these cannot be relied upon as regular sources of funds for the long term support of the data curation effort. A third option is to utilize both regular, budgeted funding as well as grants to augment any shortfalls.

\section{Ensuring continuity}

There remains one final challenge: how to ensure the continuity of the data curation effort in the face of possible changes in the institution's leadership, meager budgets, and unwilling researcher or staff participation in implementing the data policy. While there are no simple solutions, I think institutionalizing a data policy, organizing and making available decades of archaeological research, preserving not just artifacts but also all associated documentation, and most importantly, disseminating information about the availability of these information resources can definitely help keep the data curation effort alive. Knowledge that these resources exist and are accessible to other researchers (who will also be subject to the terms of the institution's data policy) will generate interest in keeping these significant information resources available for the long term.

\section{Conclusion}

Transitioning from simple, per-project research data storage methods to institutional data curation is not easy and it is not undertaken lightly. But ensuring the preservation of and long-term access to archaeological materials and research data are also not responsibilities that the institution can turn away from. By using a well-crafted data policy to lay the groundwork for data sharing, data reuse, and data openness, the institution's data curation initiatives can further enhance its critical role in archaeological research, allowing it to fulfill its mandate of being the leading archaeological research institution in the country.

\section{References}

About Databib. (n.d.) About Databib. Retrieved from http://www.databib.org/about.php

Anderson, D., Hermann, N., Miller, S., \& Yerka, S. (2011). Archaeological Information System Standard Design Concepts. Digital Data Interest Group Electronic Symposium, SAA 2011. Retrieved from http://visiblepast.net/see/archives/1066

Banning, E. B. (2000). The archaeologist's laboratory: The analysis of archaeological data. New York: Kluwer Academic/Plenum.

Beachboard, J., \& Aytes, K. (2011). Information orientation, information technology governance, and information technology service management: A multi-level approach for teaching the MBA core information systems course. Journal of Information Technology Education: Research, 10, 139-160. Retrieved from http://www.jite.org/documents/Vol10/JITEv10p139-160Beachboard949.pdf

Berglund, Y. (2005). A life after the project - continuation and sustainability. Retrieved from http://www.ahds.ac.uk/creating/information-papers/project-continuation/index.htm

Boock, M., \& Chadwell, F. (2010). Steps toward implementation of data curation services at Oregon State University libraries. Retrieved from http://ir.library.oregonstate.edu/xmlui/bitstream/handle/1957/20593/DataCurationReportMichaelFaye2 01007.docx 
Bustard, W. (2000). Archaeological curation in the 21st century or, making sure the roof doesn't blow off. Cultural Resource Management, 5, 10-15.

Coombs, C. H. (1964). A theory of data. New York: Wiley.

Crankshaft Publishing. (n.d.). The nature of archaeological data (Discovering barbarian Europe). Retrieved from http://what-when-how.com/ancient-europe/the-nature-of-archaeological-data-discoveringbarbarian-europe/

Day, M. S. (2010). Curation of research data. Retrieved from http://www.slideshare.net/michaelday/curation-of-research-data

DHCuration. (n.d.). FAQs on data curation. Retrieved from http://guide.dhcuration.org/faq/

Fosdick, H. (1985). IRM: Putting theory to work. Infosystems, 32(8), 33-34.

Goldfine, A. H. (1982). Database directions: Information resource management-Strategies and tools. Washington, D.C.: U.S. Dept. of Commerce, National Bureau of Standards NBS 500-92.

Grant, J., Gorin, S., \& Fleming, N. (2008). The archaeology coursebook: An introduction to themes, sites, methods, and skills. New York: Routledge.

GSLIS. (n.d.). Data curation. University of Illinois' Graduate School of Library \& Information Science. Retrieved from http://www.lis.illinois.edu/academics/programs/ms/datacuration

Greene, K. (1995). Archaeology: An introduction (3rd ed.). UK: Routledge.

Guimaraes, T. (1985). IRM revisited. Datamation, 31(5), 130-134.

Hemsoth, N. (2012a). The evolving art (and business) of data curation. Retrieved from http://datanami.com/datanami/2012-01-12/the evolving art of data curation.html

Hemsoth, N. (2012b). A “Jurassic Park" for archaeological data. Retrieved from http://datanami.com/datanami/2012-01-30/a_jurassic_park_for_archeological_data.html

Horton, F. (1981). Information resources management (IRM): Where did it come from and where is it going. In Proceedings of the $A C M$ ' 81 conference ( $A C M$ ' 81 ), Beth Levy (Ed.). ACM, New York: USA, 277-278.

Horton, F. (1983). The knowledge gateway system to information access. Computerworld, pp. 9-18.

Jones, S. (2009). A report on the range of policies required for and related to digital curation, version 1.2. Glasgow: DCC, pp. 29-31. Retrieved from http://www.dcc.ac.uk/sites/default/files/documents/reports/DCC_Curation_Policies_Report.pdf

Knox, K.T. (2007). The various and conflicting notions of information. Issues in Informing Science and Information Technology, 4, 675-689.

Lock, G. R. (2003). Using computers in archaeology: Towards virtual pasts. London: Routledge.

Marchand, D. (1978). Information management in public organizations: Defining a new resource management function. The Bureaucrat, pp. 4-10.

Mayernik, M. S., Choudhury, G. S., DiLauro, T., Metsger, E., Pralle, B., Rippin, M., \& Duerr, R. (2012). The data conservancy instance: Infrastructure and organizational services for research data curation. $D$ Lib Magazine, 18(9/10). Retrieved from http://www.dlib.org/dlib/september12/mayernik/09mayernik.html

Miller, B. B. (1981). Information resource management: Theory applied. In Proceedings of the ACM ' 81 conference, Beth Levy (Ed.). ACM, New York, NY, USA, 279-280.

Moody, D. (2003). Using the world wide web to connect research and professional practice: Towards evidence-based practice. Informing Science: the International Journal of an Emerging Transdiscipline, 6, 31-48. Retrieved from http://www.inform.nu/Articles/Vol6/v6p031-048.pdf 
Niven, K., \& Thompson, M.S. (2011). Guides to good practice. Archaeology Data Service. Retrieved from http://guides.archaeologydataservice.ac.uk/g2gp/ArchivalStrat 1-0

Open data and content (n.d.). Open definition. Retrieved from http://www.opendefinition.org

Palmer, C. L. (2010). Deluge of scientific data needs to be curated for long-term use. PHYSorg.com, Feb. 24, 2010. Retrieved from http://phys.org/news186233278.html

Renfrew, A. C., and Bahn, P. (2008). Archaeology: Theories, Methods, and Practice (5th ed.). London: Thames \& Hudson.

re3data.org FAQs. Retrieved from http://www.re3data.org/faq

Richards, J. D., \& Ryan, N. S. (1985). Data processing in archaeology. Cambridge: Cambridge University Press.

Ryan, N. S. (n.d.). Managing complexity: Archaeological information systems past, present and future. Retrieved from http://www.cs.kent.ac.uk/people/staff/nsr/arch/baas.html

Semple, N. (2006). Digital repositories. Retrieved from http://www.dcc.ac.uk/resources/briefingpapers/introduction-curation/digital-repositories

Stellagroup (2012). STELLA Unconference, Brooklyn College Library (CUNY), November 9-10, 2012. Retrieved from http://stellagroup.wordpress.com/data-curation-notes/

Sullivan, L. P., \& Childs, S. T. (2003). Curating archaeological collections: From the field to the repository. Archaeologists Toolkit 6. Lanham, MD: AltaMira Press.

The Society for Historical Archaeology. (1993). Standards and guidelines for the curation of archaeological collections. In The Society for Historical Archaeology Newsletter, 26, 4.

Trauth, E. M. (1988). The evolution of information resource management. Information \& Management, 16, 257-268

Waraksa, E. A. (2011). Digging into archaeological data. EDUCAUSE Review, 46(5), 10-11. Retrieved from http://www.educause.edu/ero/article/digging-archaeological-data

\section{Biography}

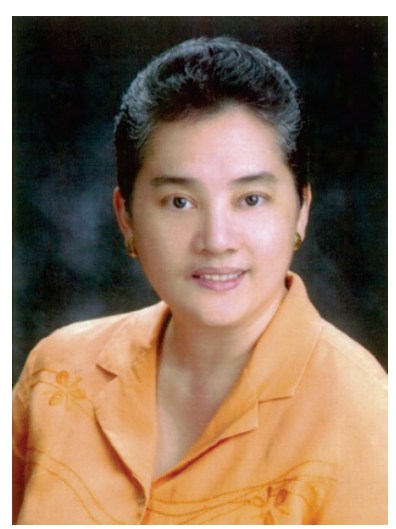

Maria Sagrario R. Simbulan is an Assistant Professor at the University of the Philippines Diliman Extension Program in Pampanga. She teaches information technology and technology management courses at the graduate and undergraduate levels. She has a Masters degree in Technology Management and a Diploma in Archaeology. She is currently working on her Ph.D. in Archaeology. Her research interests include the use of IT in society, user interface design, learning objects, database design and development, the use of technology in teaching and learning, and the archaeological applications of IT.

Email: msrsimbulan@up.edu.ph 